\title{
ANOTAÇÕES CRONOLÓGICAS SOBRE A TRAJETÓRIA DO SERVIÇO \\ SOCIAL NO SISTEMA DE SAÚDE EM PORTUGAL
}

Sónia Guadalupe ${ }^{1}$

\section{RESUMO}

O presente artigo sistematiza em breves notas cronológicas alguns passos do caminho de alargamento e consolidação do espaço profissional do Serviço Social no sistema de saúde em Portugal. As anotações aqui apresentadas pretendem contribuir para organizar os principais marcos históricos e legislativos, do período que decorre entre 1924 e 2010, atravessando um percurso que centramos no Serviço Social em articulação com o contexto sociopolítico nacional e global em que se insere.

PALAVRAS-CHAVE: Serviço Social, Saúde, Cronologia, Sistema de Saúde Português

\section{INTRODUÇÃO}

A relação do Serviço Social com a área da saúde remonta às origens da profissão. Martinelli (2003, p. 9) afirma mesmo que esta é de tal forma intensa que “mais do que intensa, tal relação é, na verdade, histórica, sendo mesmo constitutiva da sua identidade profissional”.

Desde logo, Mary Richmond (1861-1928 EUA), considerada pioneira e criadora do Serviço Social foi fortemente influenciada por Florence Nithtingale, fundadora da enfermagem moderna, nomeadamente pela sua proposta da figura das visitadoras da saúde como uma estratégia operacional que Richmond traz para o Serviço

\footnotetext{
${ }^{1}$ Assistente social, licenciada em Serviço Social, Mestre em Família e Sistemas Sociais, Doutorada em Saúde Mental. Professora Auxiliar Instituto Superior Miguel Torga, Portugal - ISMT e investigadora do Centro de Estudos da População, Economia e Sociedade - CEPESE. E-mail: guadalupe@ismt.pt, soniaguadalupe@gmail.com
}

Revista Serviço Social \& Saúde. UNICAMP Campinas, v. X, n. 12, Dez. 2011 
Social de forma desenvolvida e ampliada. Os registos históricos apontam para a presença dos “visitadores domiciliares” nas equipas de saúde antes de 1890, tendo sido esta a primeira face visível do Serviço Social nos Estados Unidos da América na viragem de século.

Em 1905, o médico Richard C. Cabot criou o primeiro Serviço Social Médico, no Hospital Geral de Massachussets, sendo a sua ação tida como valiosa e indispensável no diagnóstico e tratamento médico-social dos doentes ambulatórios ou internados (CABOT, 1928 apud COWLES, 1993), ao designar Garnet I. Pelton para desempenhar funções de Serviço Social. A sua sucessora, Ida Cannon (1923, apud COWLES, 2003) aponta como estando no cerne da introdução do Serviço Social nos contextos médicos, o facto dos cuidados médicos terem passado a fazer-se quase unicamente no contexto do gabinete médico ou no hospital, restringindo o seu campo de visão e colocando-o centrado nos fatores fisiológicos. Estas mudanças abriram uma brecha para a integração de outras perspectivas tidas, inicialmente, como complementares e compensatórias da intervenção clínica. Aliás, a principal incumbência do Serviço Social, neste contexto, era a redação de relatórios que descrevessem a situação e condições habitacionais e de trabalho dos doentes.

Para além desta concepção compensatória decorrente das reestruturações dos modelos assistenciais da Medicina, “o trinómio higiene, educação e saúde [...] caracteriza o Serviço Social nas suas origens, [tendo deixado] marcas bastante profundas em sua identidade e no modelo clássico de Serviço Social” (MARTINELLI, 2003, p. 10).

O processo de génese e emergência do Serviço Social na saúde em Portugal ancora em concepções teóricas e em práticas médico-sociais com influência do positivismo e cientismo, na transição entre os séculos XIX e XX (MATIAS, 2003, p. 
91). Os Debates em torno da Medicina Moderna (englobando o Movimento Higienista, a Medicina Social e a Preventiva) e o contacto que se fazia com experiências noutros países, para além das necessidades identificadas no contexto social, levam a posicionamentos vários entre a Medicina e o próprio poder político no sentido de introduzir novas formas de intervenção na área da saúde.

No seguimento da formação dos primeiros assistentes sociais em Portugal, nos anos 50 criam-se movimentos de reflexão e avaliação crítica no seio da profissão, sendo que “o Serviço Social queria libertar-se de uma doutrina de 'higienismo social' e de uma atuação assistencialista, paliativa e casuística para fomentar uma intervenção social que fosse sistematizada promocional e global” (PORTUGAL-MS, 1998, p. 5).

Todo um processo de conquistas decorreu, tendo um fôlego renovado com as profundas transformações nos anos 70 do século XX em Portugal. A partir daqui tornase incontornável a discussão centrada na relação com os sistemas de saúde, as políticas de saúde e as políticas sociais que atravessam a prática quotidiana dos assistentes sociais que trabalham em unidades de prestação de cuidados de saúde, nos diversos níveis do sistema, que entretanto se instituiu em Portugal e dura até aos dias de hoje, apesar dos reveses que tem conhecido: o Serviço Nacional de Saúde. A partir da sua criação têm sido "trinta anos de caminhada difícil, mas vitoriosa” como refere o seu principal instigador, António Arnaut (2009, p. 17), que assume o SNS como a grande causa da sua vida.

O Serviço Social tem sido um dos atores do sistema de saúde português, constituindo uma carreira já com longo percurso de mais de um século a nível internacional, e de mais de meio século em Portugal.

Na evolução dos sistemas de saúde não podemos deixar de referir as transformações instituídas por uma visão das questões da saúde e da doença informada 
pelos modelos biopsicossocial e holístico da saúde que se distanciaram do modelo biomédico, redutor e mecanicista. Tais modelos são cruciais na construção social da saúde, tendo feito emergir outras dimensões na intervenção na saúde e na doença, antes ignoradas ou secundarizadas, e introduziram também novas dinâmicas de intervenção em equipa multidisciplinar, onde ganham espaço outras profissões que não apenas as mais centradas no tratamento da dimensão fisiológica. A visão holística, da pessoa como um todo e das questões da saúde na sua complexidade, defende também novos papéis, tanto para o doente e sua família, como para os profissionais, trazendo desafios a que os princípios da profissão, assim como o conteúdo funcional que tem assumido neste campo profissional, respondem claramente.

A prática profissional dos assistentes sociais é determinada por um jogo de forças e relações sociais das quais não pode dissociar-se, identificando, numa leitura ecossistémica, um conjunto de determinantes políticas e organizacionais que se refletem na sua prática e no seu enquadramento institucional. Dá-se numa “realidade social concreta inserida num quadro geral que é o contexto sócio-histórico e cultural” (BAPTISTA, 2001, p. 17).

A relação do Serviço Social com as políticas de saúde em Portugal pauta-se pelo seu caráter operativo e participativo ou propositivo nos diferentes níveis da sua ação. Diz-nos Myrian Veras Baptista (2001, p. 17-18) que a “prática profissional concreta, quotidiana, exprime não apenas a capacidade técnico-operativa de quem a realiza, mas também, e principalmente, [a] sua posição existencial, política e ideológica face às relações da sociedade em que vive. [...] A prática profissional dos assistentes sociais é uma prática que lida fundamentalmente com as políticas sociais: esta é a sua ‘matéria-prima””, sendo este profissional um “agente político por excelência”. 
É a assunção de uma função que ultrapassa o papel meramente operativo que leva o assistente social a ter na sua mira um papel de agente ativamente implicado no seu trabalho, colocando-o num nível de inscrição (como diria José Gil na sua obra Portugal Hoje, o Medo de Existir?) que permite ultrapassar o plano mais acessível do quotidiano. Este propósito é assumido no documento produzido por um grupo de trabalho de assistentes sociais no final dos anos 70 do século $\mathrm{XX}$ onde se afirma que "são objetivos do Serviço Social participar na definição, reformulação, execução e avaliação de políticas de saúde” [...], "assumindo-se como agentes de prevenção, promoção, recuperação e reabilitação da Saúde, entendida como um valor coletivo" (PORTUGAL-GEPS, 1979, p. 4). A participação dos assistentes sociais na política social e de saúde, neste caso, exige capacidade de análise crítica, pertinência, muita fundamentação e persistência, o que nem sempre escapa a trajetórias labirínticas e que ganham significado em conquistas frequentemente muito pouco visíveis.

\section{Contributo para uma cronologia do Serviço Social na Área da Saúde em Portugal}

Apesar do espaço conquistado e da reconhecida relevância da intervenção do Serviço Social na área da saúde, há um caminho de alargamento e consolidação que prossegue. Parece-nos, por isso, interessante rever em breves notas alguns passos desse caminho.

É na senda do conhecimento do percurso da profissão nesta área e da sistematização dos diferentes vetores e desafios que atravessam hoje o Serviço Social neste domínio de intervenção social, que assume facetas diversas e complexas, que aqui deixamos este contributo, apesar de sempre incompleto. 
Centramos a cronologia no Serviço Social, não o desligando do contexto sociopolítico nacional e mais global que se reflete no Sistema de Saúde. Fazemos, no entanto, apenas breves referências a este contexto, nomeadamente a alguns marcos históricos e legislativos fundamentais, pois a história do Sistema de Saúde Português encontra-se bem documentada.

\section{4}

O primeiro ensaio de Serviço Social em Portugal ocorre no sanatório de Lisboa por iniciativa do médico Pacheco de Miranda, seu diretor, que conhecia os trabalhos de Cabot e Richmond na América e as experiências francesas (MARTINS, 1999, p. 75). Este encara a assistente social “como monitora de higiene e educadora das famílias, alguém que elabora um diagnóstico social e considerará cada caso como um problema [...]. O principal objetivo era organizar e estudar os fatores da decadência e de miséria a fim de concorrer para a sua supressão” (apud MARTINS, 1999, p. 76). Pacheco de Miranda elaborou ainda o breviário das Senhoras Assistentes Sociais do Serviço Social do Sanatório: reconhece a necessidade de aquisição de conhecimentos específicos (“métodos científicos”) (idem).

\section{5}

Branca Rumina relata, em sessão da Sociedade das Ciências Médicas de Lisboa, as impressões de formações e viagens a França e outros países "no tocante a um processo moderno de assistência a necessitados - o Serviço Social no hospital” (apud MATIAS, 1999, p. 110). Descrevendo a sua ação, refere que “o Serviço Social acompanha os doentes e verifica se os tratamentos são cumpridos corretamente, apoia o doente e a família moral e materialmente [...] [considerando-o] um agente de ligação” (ibid.). Termina apelando para a necessidade de se instituir o Serviço Social Hospitalar em Revista Serviço Social \& Saúde. UNICAMP Campinas, v. X, n. 12, Dez 2011 
Portugal “por ser um precioso e indispensável auxiliar, com incontestáveis vantagens para o hospital e para os doentes” (ibid.). Para tal, "as assistentes sociais precisam ter 'noções de higiene, de medicina e certa experiência do que seja a miséria social' e de colaborar em perfeita harmonia [...] [no sentido de] completar a obra do médico” (apud MARTINS, 1999, p. 77-8). Na mesma sessão, Pacheco de Miranda refere que a intervenção hospitalar é limitada, “considerando os doentes de forma isolada do seu meio sem ter em conta as causas e consequências sociais da doença mas apenas a sua patologia clínica” (apud MATIAS, 1999, p. 110).

1930

Branca Rumina publica um artigo intitulado "um aspeto da assistência ao lactante em Lisboa", em que diz proceder segundo os ensinamentos do "Serviço Social de Casos Individuais", referindo que este “é cada vez mais usado em matéria de assistência” (MATIAS, 1999, p. 109).

1932

Alfredo Trovar de Lemos, diretor do Dispensário de Higiene Social de Lisboa, escreve o livro “O Serviço Social de Assistência Social”, considerado como “a preparação técnica indispensável para as assistentes sociais” (MATIAS, 1999, p. 109).

1934

Alfredo Trovar de Lemos dá um curso de visitadoras, baseando-se no referido livro e abordando os "perigos sociais". Referiu-se a tal curso como o " $1^{\circ}$ curso de assistentes sociais” (apud MARTINS, 1999). Alfredo Trovar de Lemos apresenta uma concepção não moralizadora do Serviço Social, diz ele: “pouco nos interessa que o doente seja honesto ou desonesto, criminoso ou não, tolerada ou mulher séria, o doente é uma 
pessoa que sofre e a quem nos compete aliviar o seu sofrimento sem inquirirmos se as suas qualidades são morais ou deixam de ser", devendo o assistente social "lutar contra o preconceito da doença vergonhosa” (apud MARTINS, 1999, p. 71). No processo de institucionalização do Serviço Social a dimensão moralista é sobrevalorizada: a profissão reflete os valores do Estado Novo e da doutrina social da igreja (ibid.).

- O Diretor do Dispensário de Puericultura de Viana do Castelo defende a criação de escolas de Serviço Social junto das Faculdades de Medicina, referindo-se ao atraso do Serviço Social no nosso país (ibid.).

1935

Inicia-se a formação de assistentes sociais em Portugal no quadro de escolas especializadas, sendo criada a primeira escola de Serviço Social, o Instituto do Serviço Social em Lisboa por iniciativa do Patriarcado de Lisboa, com suporte jurídico da Associação de Serviço Social. Inicia o seu funcionamento com estatuto de ensino particular e feminino sob a direção da Condessa de Rilvas e com direção técnica de Marie Thérèse Lévêque (francesa diplomada em Enfermagem e Serviço Social) (FERNANDES, 1985; MARTINS, 2010). Passa a designar-se como Instituto Superior de Serviço Social em 1969.

1937

É criada a Escola Normal Social em Coimbra, com base na necessidade de formação de quadros especializados para integrarem o "Ninho dos Pequenitos”, a Obra de Protecção à Grávida e à Criança de Coimbra, dirigido por um grupo de francesas da Congregação “Franciscanas Missionárias de Maria”, das quais se destaca Constance Davon que propõe um curso de puericultura e de formação social dirigido às raparigas da alta sociedade de Coimbra (MARTINS, 2010), tendo-se inscrito 42 raparigas, garantindo a Revista Serviço Social \& Saúde. UNICAMP Campinas, v. X, n. 12, Dez 2011 
abertura da escola como escola de puericultura e de Serviço Social ou como centro médico-pedagógico e de higiene social (ibid.). A sua criação tem o apoio de figuras destacadas da cultura e da política, destacando-se o Professor Bissaya Barreto, através da Junta da Província da Beira Litoral, que integrava o “Comité Activo” da Escola. Esta assume a designação de Escola Normal Social - A Saúde por analogia com a Ecole Normale Sociale de Paris e passa a designar-se Instituto Superior de Serviço Social de Coimbra em 1962 (ISSSC, 1985). Atualmente o curso de Serviço Social é a licenciatura histórica do Instituto Superior Miguel Torga (que é a designação atual da instituição).

1938

A Câmara Municipal de Leiria cria um Dispensário de Higiene concebido pelo seu diretor, Duarte Gorjão Henriques, como um “centro de ação social” e como “centro de saúde regional” tendo por missão coordenar os serviços sociais de proteção e assistência à maternidade e infância e de sanidade e profilaxia nesta área (MARTINS, 2010, p. 267), colocando sob responsabilidade do Serviço Social "os inquéritos às condições de vida das famílias necessitadas de proteção ou assistência, os inquéritos de natalidade e a ação de profilaxia social” (HENRIQUES, 1940 apud MARTINS, 2010).

1939

É publicado o Decreto-lei 30135 que regulamenta o funcionamento e os programas das “Escolas de Formação Social” (ISSSC, 1985; FERNANDES, 1985).

\section{1}

Esta é a data mais frequentemente veiculada em fontes informais como marcando a admissão da primeira assistente social nos Hospitais da Universidade de Coimbra. Este será um marco atribuído a João Porto, médico e diretor da Faculdade de Medicina da 
Universidade de Coimbra e dos Hospitais da Universidade de Coimbra (de 1941 a 1946), autor de um texto intitulado "Serviço Social e o Hospital - outras possibilidades de participação dos Hospitais da Universidade de Coimbra no Serviço Social em Coimbra” publicado como separata da Coimbra Médica em 1940, onde apresenta a proposta de organização do Serviço Social nestes hospitais (MARTINS, 2010, p. 266). Tendo fundado o Centro de Cardiologia Médico-Social em Coimbra, integra estágios da Escola Normal Social (designada mais tarde por Instituto Superior de Serviço Social de Coimbra) e posteriormente uma assistente social. É provável que seja a esta assistente social que se referem em 1941. No entanto, Alberto Morão (1994, p. 405), citando o texto “Dez anos de história dos HUC” de 1953, refere que o Serviço Social é criado em julho de 1946 com uma assistente social privativa do Centro de Cardiologia, tendo apenas em 1950 sido criado o lugar de assistente social nos Hospitais da Universidade de Coimbra, lugar ocupado por Maria da Luz Sanches Pinto.

\section{2}

É admitida a primeira assistente social no Hospital Psiquiátrico Júlio de Matos em Lisboa, Maria Gabriela Moreira Sales, através de Barahona Fernandes (MARTINS, 1999, p. 180-83). Este considerava que as funções do Serviço Social (realização de inquéritos sociais às famílias, vigilância dos doentes, ação orientadora e educativa, preparação do meio para a alta e para a readaptação do doente, fazendo a prevenção das recaídas) permitiam estabelecer “o elo de ligação entre o hospital e a população, aumentando o rendimento dos serviços e alargando consideravelmente o seu campo de ação e benefícios”, acrescentando que “passou a dominar na assistência psiquiátrica o pensamento social, o desejo profilático, exercido sobre o meio ambiente” (apud MARTINS, 1999, p. 182). 


\section{5}

Prevê-se a organização do Serviço Social nos centros de assistência psiquiátrica, dispensários, hospitais e asilos psiquiátricos através da Lei n. ${ }^{\circ} 34502$ de 18 de abril de 1945, integrando assistentes sociais e visitadoras sociais (MARTINS, 2010). O Regulamento dos serviços do Centro de Assistência Psiquiátrica da zona Centro (Decreto-lei n. ${ }^{\circ} 34547$ de 28 de abril de 1945) no seu artigo $17^{\circ}$ descreve a equipa do Serviço Social do Hospital Sobral Cid com médicos, assistentes sociais e visitadoras sociais (ibid.). Atente-se a curiosidade de a legislação definia que o seu recrutamento implicaria um concurso documental que atenderia às habilitações profissionais, idade e comportamento moral (ibid.).

\section{6}

É discutida a lei orgânica hospitalar na Assembleia da República. Defende-se o Serviço Social para estabelecer o diagnóstico social na complementaridade do diagnóstico clínico.

Lei da Organização Hospitalar (Lei 2011/46 de 2 abril). Introduz a imprescindibilidade do diagnóstico social como complemento do clínico. Inclui nos serviços hospitalares o Serviço Social (bases VIII, IX e XX). Lança três aspetos que hoje ainda subsistem como caracterizando o Serviço Social na saúde: o seu caráter subsidiário, apenas intervindo quando havia necessidade de desbloquear fatores inerentes à situação da doença vivida pelo sujeito e entreves à sua recuperação e integração (regime de chamada, p. ex.); a sua função humanizadora, na relação trifacetada doente-família-médico; o seu papel mediador pela aplicação mais justa dos socorros, como então se dizia, considerando-o como elo de ligação entre os Serviços de Saúde e o meio social (TELES, 1990; PORTUGAL-MS, 1998). Através desta lei “o Serviço Social passa a estar contemplado 
nos hospitais centrais, regionais e sub-regionais [...] e nos dispensários antituberculosos e de higiene social” (MARTINS, 2010, p. 267).

\section{8}

É admitida a primeira assistente social no Instituto Português de Oncologia em Lisboa (MATIAS, 2001), Maria Carolina Veiga Ferreira, coadjuvada por auxiliares sociais, sendo assim o Serviço Social criado por Francisco Gentil.

É constituída a Organização Mundial de Saúde (OMS/WHO, World Health Organization), agência internacional das Nações Unidas para a saúde, com sede em Genebra (Suíça), no dia 7 de abril, tendo sido este instituído como "Dia Mundial da Saúde”.

1956

É criado o Instituto de Serviço Social, no Porto, pela Associação de Cultura e Serviço Social por iniciativa de D. António Ferreira Gomes (FERNANDES, 1985).

\section{1}

Os cursos de Serviço Social são considerados cursos superiores por Despacho do Ministério da Educação de 20 de outubro² .

1963

O Estatuto de Saúde e Assistência (Lei 2120 de 15 de julho) inclui o Serviço Social nos hospitais regionais, na intervenção individual e familiar, de grupo ou comunidade e na execução da política social (TELES, 1990).

\footnotetext{
${ }^{2}$ Relativamente à criação de cursos de Serviço Social, apenas referimos os três primeiros a ser instituídos, considerados os "históricos". 
1968

Estatuto Hospitalar (Decreto-lei 48357/68) define a natureza da ação dos estabelecimentos hospitalares como simultaneamente médica e social. Define como princípios orientadores da ação social o estabelecimento das "relações entre as necessidades pessoais ou familiares e os casos de doença”, a envolver na intervenção para o “regresso ao meio social”, e a promoção de contactos dos doentes e familiares com serviços da comunidade. Reconhece ainda o papel da investigação nas "ciências médicas sociais” (PORTUGAL-MS, 1998, p. 6).

Regulamento Geral dos Hospitais (Decreto-lei 48358/68) inclui o Serviço Social nos serviços assistenciais (art. $10^{\circ}$ ) e o assistente social no Conselho Técnico (art. $8^{\circ}$ ), definindo como competências para o Serviço Social Hospitalar (art. 97º): colaboração com serviços de ação médica (causas e consequências sociais da doença), o "remediar estados de crise ou carência dos doentes” através de contactos internos e externos, e a “colaboração técnica às iniciativas particulares” e de voluntariado, orientando-as e coordenando-as (TELES, 1990, p. 40; PORTUGAL-MS, 1998, p. 6).

Direção Geral dos Hospitais, através da ITAS (Inspecção Técnica de Acção Social, entidade que supervisionava e coordenava a atividade do Serviço Social nos hospitais), define as funções do Serviço Social Hospitalar (TELES, 1990).

\section{1}

É reconhecida a necessidade de Serviço Social nos centros de saúde (Decreto-Lei 413/71) no contexto da reforma sob a égide de Gonçalves Ferreira (1989; 1990), que coloca no eixo central do sistema os cuidados de primeira linha ou essenciais, promovendo a integração funcional de serviços dispersos, e reconhecendo o direito à saúde a toda a população, o que abre caminho à universalização dos cuidados. Esta 
legislação é descrita por Gonçalves Ferreira (1990, p. 344) como “a pedra no charco pantanoso em que nos encontrávamos”, atendendo à doutrina defendida e pela estrutura de serviços proposta.

1973

É aprovado o documento “Regulamento do Serviço Social” pela Secretaria de Estado da Saúde (29 de novembro de 1973), que elenca em 17 artigos a definição de funções do Serviço Social hospitalar. Este é tido como orientador do exercício profissional, referindo que "a ação do hospital é simultaneamente de natureza médica e social. Neste contexto, enquanto a ação médica se destina, principalmente à cura e reabilitação dos doentes, a ação do Serviço Social visa detetar os fatores psicossociais que, interferindo na doença, possam dificultar a sua cura e reabilitação”. Este documento teve por base um projeto de funções apresentado pela ITAS denominado "Especificidade do Serviço Social Hospitalar”.

\section{6}

Na sequência da Revolução do 25 de Abril de 1974, a Constituição da República Portuguesa consagra o Artigo $64^{\circ}$ à Proteção da Saúde, proclamando que "todos têm direito à proteção da saúde e o dever de a defender e promover”, indicando como este se realiza e as incumbências principais do Estado, anunciando a criação de um Serviço Nacional de Saúde. Apesar deste ser o único artigo que se refere expressamente à saúde, encontram-se, contudo, na Constituição outros preceitos que lhe dizem respeito: o Direito à Vida (Art. 24º ), o Direito à Integridade Pessoal (Art. 25), o Direito ao Ambiente e Qualidade de Vida (Art. 66º), entre outros de forma indireta. 
1978

A Associação dos Profissionais de Serviço Social (APSS) é juridicamente constituída.

A Declaração de Alma-Ata (que resulta da Conferência Internacional sobre Cuidados Primários de Saúde) reafirma o conceito de saúde promovido pela Organização Mundial de Saúde enfatizando o direito à saúde para todos como um direito humano fundamental e um dever individual e coletivo dos povos, salientando a luta contra as desigualdades nas políticas de saúde a nível mundial, colocando os cuidados primários no centro.

\section{9}

É aprovado por despacho de 4 de dezembro de 1979 do Secretário de Estado da Saúde, António Correia de Campos, e divulgado o documento de trabalho “O Serviço Social no Sector da Saúde” do Gabinete de Estudos e Planeamento da Secretaria de Estado da Saúde (PORTUGAL-GEPS, 1979). Este foi elaborado por um grupo de trabalho criado por despacho de 23 de maio de 1979 da mesma entidade, constituído na sua maioria por assistentes sociais de serviços de saúde. Sistematiza os conceitos, objetivos, a estrutura funcional e orgânica, assim como as funções do Serviço Social. O texto é publicado no sexto número dos Cadernos da APSS, em setembro de 1979, para garantir uma difusão a toda a categoria profissional.

Após a consagração do Serviço Nacional de Saúde (SNS) no texto da Constituição da República Portuguesa de 1976, António Arnaut, Ministro dos Assuntos Sociais à data, prepara a Lei de Bases que daria execução à disposição constitucional. Após intenso debate político, só em 15 de setembro de 1979 é publicada a Lei n. ${ }^{0}$ 56/79, conhecida como a Lei de Bases do SNS ou "Lei Arnaut". O SNS é instituído como sendo de caráter universal, geral e gratuito. 
1983

O Regulamento dos Centros de Saúde (Despacho Normativo 97/83 de 22 de abril) define o centro de saúde como uma unidade integrada, polivalente e dinâmica, prestadora de cuidados primários, que visa a promoção e a vigilância da saúde, a prevenção, o diagnóstico e o tratamento da doença, dirigindo-se, globalmente, a sua ação ao indivíduo, à família e à comunidade. No artigo $70^{\circ}$ estabelece que "o Serviço Social do centro de saúde é constituído por técnicos de Serviço Social, em princípio, na base de 1 técnico por 30 mil habitantes”. As suas atribuições são definidas no artigo $71^{\circ}$.

1985

A Inspecção Técnica de Acção Social (ITAS) publica o documento “As funções do Técnico de Serviço Social” (Direcção Geral dos Hospitais) (PORTUGAL-MS, 1998).

1986

O Despacho 26/86 institui o Gabinete do Utente. Este é um serviço “destinado a receber as sugestões e reclamações dos utentes” e define-o como simultaneamente, um instrumento de gestão dos serviços e um meio de defesa dos utentes. Estipula as suas atribuições e o seu funcionamento "junto do Serviço Social de cada estabelecimento hospitalar e nas sedes das administrações regionais de saúde”.

1989

A revisão constitucional altera a alínea a) do n. ${ }^{\circ} 2$ do artigo $64 .^{\circ}$, estabelecendo que 0 direito à proteção da saúde é realizado através de um SNS “universal e geral e, tendo em conta as condições económicas e sociais dos cidadãos, tendencialmente gratuito”, substituindo a expressão “gratuito”. 
1990

Em 1990 é aprovada a Lei de Bases da Saúde (Lei 48/90 de 24 de agosto) que marca até hoje as políticas de saúde e a organização da rede de serviços do Sistema de Saúde Português, sendo regulamentada passados três anos através do Decreto-Lei 11/93. Foi posteriormente alterada pela Lei n. ${ }^{0}$ 27/2002, de 8 de novembro, introduzindo um novo regime de gestão hospitalar aplicável aos estabelecimentos hospitalares que integram a rede de prestação de cuidados de saúde, prevendo modelos de gestão de tipo empresarial.

1991

Tendo sido aprovado o curso de licenciatura em Serviço Social em 1990 (Portaria 15/90 do Ministério da Educação), é criada a carreira de Técnico Superior de Serviço Social (Decreto-Lei 296/91 de 16 de agosto).

1998

Divulga-se o documento “Serviço Social da Saúde” do Departamento de Recursos Humanos da Saúde do Ministério da Saúde, organiza a informação e estrutura o enquadramento funcional do Serviço Social. O documento teve origem na necessidade de enquadramento orgânico e definição funcional da carreira técnica superior, tendo por base a iniciativa da coordenação do Serviço Social do Subgrupo Hospitalar Santo António dos Capuchos/Desterro/Arroios, tendo sido constituído um grupo de trabalho. As metas que pretenderam atingir foram: a sistematização do conteúdo funcional do Serviço Social da Saúde (com delineamento de funções, hierarquias, objetivos, atividades e técnicas); a definição da carreira e enquadramento orgânicos nas áreas de atuação; o levantamento dos recursos humanos existentes e a determinação das necessidades de assistentes sociais nos cuidados primários e diferenciados Revista Serviço Social \& Saúde. UNICAMP Campinas, v. X, n. 12, Dez. 2011 
(PORTUGAL-MS, 1998, p. 8). Integrou este documento um relatório de um estudo produzido sobre as funções do Serviço Social na Saúde que avaliou as funções na sua dimensão operacional (objetivos e ações) e os processos de intervenção dos assistentes sociais que constituíram a amostra ( $\mathrm{N}=222)$ (Ibid.).

O Despacho Conjunto n. ${ }^{\circ}$ 407/98 de 18 de junho, dos Ministérios da Saúde e do Trabalho e da Solidariedade Social, relativo à intervenção articulada do apoio social e dos cuidados de saúde continuados, trouxe fortes desafios aos assistentes sociais, tendo por objetivos: a intervenção articulada da saúde e da ação social; o aproveitamento e racionalização dos recursos existentes; a promoção da autonomia das pessoas em situação de dependência; reforço das capacidades e competências das famílias; prioridades à prestação de cuidados no domicílio.

É publicada a Lei de Saúde Mental (Lei n. ${ }^{\circ}$ 36/98 de 24 de julho) que estabelece os princípios gerais da política de Saúde Mental e regula o internamento compulsivo dos portadores de anomalia psíquica, designadamente das pessoas com doença mental. Enuncia como princípios gerais a prestação de cuidados ao nível da comunidade, no meio menos restritivo possível, evitando o afastamento dos doentes do seu meio habitual e a facilitar a sua reabilitação e inserção social. Indica que para a reabilitação psicossocial, a prestação de cuidados deve ser assegurada em estruturas residenciais, centros de dia e unidades de treino e reinserção profissional, inseridos na comunidade e adaptados ao grau específico de autonomia dos doentes (artigo $3^{\circ}$ ). A lei defende ainda que a prestação de cuidados deverá ser assegurada por equipas multidisciplinares habilitadas a responder aos aspetos médicos, psicológicos, sociais, de enfermagem e de reabilitação. No ano seguinte, o Decreto-Lei n. ${ }^{0}$ 35/99 estabelece a organização da prestação de cuidados de Psiquiatria e Saúde Mental. 
1999

Publica-se o "regime de criação, organização e funcionamento dos centros de saúde"

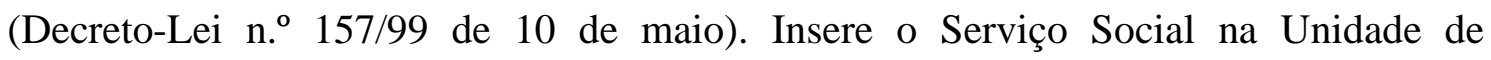
Cuidados na Comunidade (artigo $13^{\circ}$ ). Esta unidade tem como missão a prestação de cuidados de enfermagem e de apoio psicossocial de base geográfica e domiciliária, com identificação e acompanhamento das famílias com situação de maior risco ou vulnerabilidade de saúde, em especial quando existam grávidas, recém-nascidos, pessoas com marcada dependência física e funcional ou com doenças que requeiram acompanhamento mais próximo e regular. A sua atividade assenta numa equipa multiprofissional que inclui enfermeiros, assistentes sociais e outros técnicos. Este diploma legal vem relegar para segundo plano o papel do Assistente Social na rede dos Serviços de Saúde, uma vez que, apenas refere no seu artigo $13^{\circ}$, a prestação de apoio psicossocial no contexto da designada "Unidade de Cuidados na Comunidade”, remetendo este apoio psicossocial para um plano complementar. É ainda de referir que “esvazia as atribuições e funções ao Serviço Social, perdendo este serviço o até então estatuto de autonomia, passando os seus recursos humanos a estarem afetos à referida unidade, sob direção de um enfermeiro, estando indefinida a hierarquia que ligava os Serviços Sociais dos Centros de Saúde a um coordenador da mesma carreira profissional” (GUADALUPE; GONÇALVES, 2009, p. 146), introduzindo "uma situação pouco clara relativamente ao estatuto dos assistentes sociais na instituição” (ibid.).

\section{2}

É divulgada a Circular Normativa do Departamento de Modernização e Recursos da Saúde do Ministério da Saúde (Circular n. ${ }^{\circ} 8$ de 16/05/02). Esta estabelece as 10 
funções que passam a vigorar nos serviços e estabelecimentos dependentes do Ministério, e aconselha a que os assistentes sociais se reportem ao respetivo órgão dirigente máximo do estabelecimento de prestação de cuidados que integram.

\section{5}

O Decreto-Lei n. ${ }^{\circ}$ 88/2005 de 3 de junho vem revogar o Decreto-Lei n. ${ }^{\circ}$ 60/2003, de 1 de abril, que pretendia criar a rede de cuidados de saúde primários, recuperando as diretrizes do Decreto-Lei n. ${ }^{\circ}$ 157/99 de 10 de maio que institui os chamados Centros de Saúde de Terceira Geração. Nesta sequência, foi criada a Missão para os Cuidados de Saúde Primários para implementar a reforma deste nível de cuidados e assim reconfigurar os centros de saúde.

\section{6}

É criada a Rede Nacional de Cuidados Continuados Integrados, no âmbito dos Ministérios da Saúde e do Trabalho e da Solidariedade Social através do Decreto-Lei n. ${ }^{\circ}$ 101/2006 de 6 de junho. A Rede, com objetivo de prestar cuidados a pessoas em situação de dependência, é constituída por unidades e equipas de cuidados continuados de saúde, e ou apoio social, e de cuidados e ações paliativas, com origem nos serviços comunitários de proximidade, abrangendo os hospitais, os centros de saúde, os serviços distritais e locais da segurança social, a Rede Solidária e as autarquias locais (segundo o artigo $2^{\circ}$ ). Nesta legislação está prevista a integração de assistentes sociais em diferentes níveis, nomeadamente nas equipas coordenadoras locais e nas equipas de gestão de altas. Esta legislação é precedida pelo Despacho 407/98 anteriormente referido, pelo Plano Nacional de Cuidados Continuados Integrados ou REDE+, Mais Autonomia, Integração, Saúde (de 13 de dezembro de 2001) e pelo Decreto-Lei n. ${ }^{\circ}$ 281/2003 de 8 de novembro, revogado pelo presente. 
É publicado o Manual de Boas Práticas para os Assistentes Sociais da Saúde na Rede Nacional de Cuidados Continuados Integrados, pela Direcção-Geral de Saúde em julho de 2006, resultado do trabalho de um grupo integrado por assistentes sociais do setor da saúde e docentes de Serviço Social.

O “Grupo de Trabalho da Saúde - Cuidados de Saúde Primários” da APSS reúne com o Grupo de Missão para os Cuidados de Saúde Primários. A reunião inscreveu-se no processo de participação da APSS no âmbito do processo de reforma dos Cuidados de Saúde Primários e visou apresentar a perspectiva da APSS sobre a proposta de LeiQuadro dos Centros de Saúde em preparação, no que se refere designadamente ao enquadramento dos assistentes sociais e do Serviço Social na reconfiguração orgânica dos Centros de Saúde.

No acompanhamento do processo de reforma dos cuidados primários, a APSS, através do seu Grupo de Trabalho para os Cuidados de Saúde Primários, promove o encontro "Os Assistentes Sociais face à Reforma dos Cuidados de Saúde Primários" a 12 de setembro de 2006.

O Decreto-Lei n. ${ }^{\circ}$ 212/2006 de 27 de outubro institui a nova Lei Orgânica do Ministério da Saúde que reorganiza os organismos que tutelam a área. Este diploma transforma as Administrações Regionais de Saúde, criadas em 1993 pelo estatuto do SNS e orientando a regionalização deste setor do Estado, em Institutos Públicos (IP), no âmbito do Programa de Reestruturação da Administração Central do Estado.

\section{7}

O Decreto-Lei n. ${ }^{\circ}$ 298/2007, de 22 de agosto, estabelece o regime jurídico da organização e do funcionamento das Unidades de Saúde Familiar (USF). Nestas o assistente social fica fora da chamada “carteira básica” de técnicos a contemplar. 
Criação dos ACES, Agrupamentos de Centros de Saúde do SNS, através do Decreto-Lei n. ${ }^{\circ}$ 28/2008, de 22 de fevereiro. Nestes reaparece a inserção do Serviço Social na Unidade de Cuidados na Comunidade (artigo $11^{\circ}$ ), sendo que esta "UCC presta cuidados de saúde e apoio psicológico e social de âmbito domiciliário e comunitário, especialmente às pessoas, famílias e grupos mais vulneráveis, em situação de maior risco ou dependência física e funcional ou doença que requeira acompanhamento próximo, e atua ainda na educação para a saúde, na integração em redes de apoio à família e na implementação de unidades móveis de intervenção”. A UCC será composta por uma equipa de enfermeiros, assistentes sociais, médicos, psicólogos, nutricionistas, fisioterapeutas, terapeutas da fala e outros profissionais, consoante as necessidades e a disponibilidade de recursos. O Serviço Social tem também enquadramento previsto artigo na Unidade de Recursos Assistenciais Partilhados (URAP), como unidade prestadora de serviços de consultoria e assistenciais às restantes unidades funcionais.

No quadro da reforma dos cuidados de saúde primários, designadamente no que toca ao processo de reconfiguração dos Centros de Saúde, a APSS, através do seu Grupo de Trabalho para os Cuidados de Saúde Primários, toma posição sobre o Serviço Social no quadro dos ACES, a 31 de outubro de 2008, designadamente sobre a inserção e lugar do Serviço Social nos novos ACES. Nesta posição a APSS apoia a concepção de trabalho multiprofissional, entendendo, no entanto, que o princípio da organização por áreas funcionais não deve prejudicar a observância de "princípios da colegialidade e da coordenação técnica e funcional, cuja relevância é reforçada pela escassez dos recursos humanos em Serviço Social na rede de cuidados de saúde primários”. A APSS sustenta que os assistentes sociais devem ser integrados na URAP (Unidade de Recursos Assistenciais Partilhados), sendo esta uma unidade funcional transversal cuja vocação 
melhor se compagina com a natureza do seu trabalho, integrando as URAP um Núcleo Operacional de Serviço Social. A APSS defende ainda que os assistentes sociais devem manter uma presença efetiva e uma participação ativa no Gabinete do Cidadão, apontando também critérios para a redefinição dos rácios de assistente social por habitante.

\section{0}

A APSS toma posição sobre o documento que define os "Requisitos para a Prestação de Cuidados em Oncologia" da responsabilidade da Coordenação Nacional para as Doenças Oncológicas que integra o Alto Comissariado da Saúde (2009) a 31 de janeiro de 2010. A APSS analisa os aspetos que apoia e contesta no documento, ressaltando o apoio à concepção de trabalho multidisciplinar e multiprofissional defendida no documento, sustentando que "os assistentes sociais devem ser integrados nas equipas multidisciplinares previstas, sem perder a sua autonomia funcional e científica, devendo ser considerados prestadores de cuidados integrados num grupo de prestadores cuja designação respeite a sua especificidade profissional”. Neste sentido, a APSS considera incompreensível e inaceitável que este não faça qualquer referência específica à integração de assistentes sociais nas equipas multidisciplinares, recomendando-o vivamente, reivindicando uma clarificação do que se entende por "cuidados de suporte” e cuidados em “psico-oncologia”, assim como a quem compete a sua prestação”.

A Comissão para os Determinantes Sociais da Saúde (CDSS-OMS, 2010) publica o seu relatório final intitulado "Igualdade na saúde através da ação sobre os seus determinantes sociais”, onde considera que reduzir as desigualdades na saúde e lutar contra as injustiças sociais é um imperativo ético. Este é um documento que merece uma reflexão muito profunda dos assistentes sociais, trazendo para o centro do debate a 
questão dos determinantes sociais da saúde e das suas interconexões com os processos de pobreza e de exclusão social.

\section{CONSIDERAÇÕES FINAIS}

O intervalo de tempo a que reportamos estas anotações cronológicas remete para períodos históricos muito diversos da sociedade portuguesa. Iniciamos o percurso de revisitação em 1924, ainda na Primeira República mas nas margens da Ditadura Nacional de 1926 que precedeu a instauração formal do Estado Novo, regime conservador, nacionalista, corporativista e autoritário que vigorou no país entre 1933 e 1974. A viragem almejada com a Revolução de 25 de Abril de 1974 traz-nos durante as décadas seguintes todo um processo de implementação de um Estado Providência, que foi sempre "quasi-providência", período também marcado pela integração na atual União Europeia. Segue-se o final de um século e início de um milénio com forte desenvolvimento social, terminando o trajeto no fecho de uma década pontuada pela incerteza e inquietação.

Na área da saúde, em traços longos, pode dizer-se "que do século XV até ao início do século XX pouco ou nada havia mudado na prestação de cuidados de saúde no nosso país” (JORGE, 1992, p. 4), tendo havido apenas pequenos ajustes ditados pelo progresso. Durante séculos, a consciência solidária de base ético-religiosa levava à organização de iniciativas para proteger os doentes, mas não havia obrigação por parte de quem os protegia, ou qualquer direito de quem era protegido, tendo este padrão caritativo-paternalista marcado o Estado Novo e resistido até aos anos setenta do século XX. Gonçalves e Costa (2003, p. 94-6) distinguem aqui 3 fases: a fase "caritativocorporativista” (até 1945, fase em que os serviços de saúde são prestados por entidades 
privadas e de cariz religioso, à exceção dos escassos serviços de sanidade geral), a fase “assistencial” (1945-1971, marcada pela lei da Organização da Assistência Social, mas pela continuidade do papel supletivo do Estado) e a fase sanitarista (após 1971, fase em que a intervenção estatal deixa de ser supletiva, assumindo a responsabilidade pela política de saúde e sua execução). Acrescentaríamos duas grandes fases posteriores: a fase do Serviço Nacional de Saúde (1976-1989, marcada pela implementação de um Sistema de Saúde Universal, geral e gratuito) e a fase da Reforma do Serviço Nacional de Saúde (de 1989 à atualidade, fase iniciada com a revisão constitucional que passa a considerar o SNS como tendencialmente gratuito e pela Lei de Bases da Saúde de 1990). Estas duas fases não são estanques, pois já durante os anos 80 os contornos do sistema de saúde que se vão definindo afastam-se do modelo consignado na Constituição (JORGE, 1992), passando os cidadãos a ser também tidos como responsáveis pela proteção à saúde, não assumindo o Estado a sua exclusividade, e generalizando a gestão privada de serviços públicos, anunciando-se o regresso ao seu papel supletivo, cada vez mais notório em anos recentes.

O processo de génese, emergência e institucionalização do Serviço Social português (MARTINS, 1999; 2010) cruza estas conjunturas sócio-históricas muito distintas, desde o período pré-republicano até à consolidação da democracia no período pós-revolucionário do último quartel do século XX. Alcina Martins (1999; 2010) sublinha a herança pesada do Estado Novo, afirmando que “o facto de a sociedade portuguesa ter vivido até ao 25 de Abril de 1974 sob um regime autoritário, conservador e obscurantista, e não ter desenvolvido nem um Estado Providência nem o conhecimento das ciências sociais, marca toda a trajetória do Serviço Social Português, com repercussão no desenvolvimento tardio do seu estatuto profissional e intelectual, 
comparativamente com o de outras áreas do conhecimento e do Serviço Social noutros países” (MARTINS, 2010, p. 292).

Ressalte-se que todo este processo é marcadamente ligado à área da saúde, tendo o Serviço Social nesta área vivido as vicissitudes dos avanços, recuos e constrangimentos da construção e consolidação do sistema de saúde. O registo das notas cronológicas dá-nos os principais marcos de um caminho sinuoso mas desafiante, em que cada conquista tem obrigado a ultrapassar muitas barreiras no prosseguimento da consolidação do espaço profissional, denunciando a ausência de uma categoria profissional (auto)regulada. Apesar das conquistas e da relevância incontestada do Serviço Social na área da saúde, há todo um percurso em aberto, motivado pela defesa dos direitos do cidadão, que é fulcral desenvolver e sustentar.

\section{ABSTRACT}

This article summarizes the main milestones in the chronology of the enlargement and consolidation of the professional domain of social work within the Portuguese health system. These notes aim at contributing to organize historical and legislative milestones in the period between 1924 and 2010. We have focused on the trajectory of social work, analysing it in conjunction with its social and political background at national and international level during this period.

KEYWORDS: Social Work, Health, Chronology, Portuguese Health System

\section{REFERÊNCIAS BIBLIOGRÁFICAS}

ARNAUT, A. Serviço Nacional de Saúde - SNS: 30 anos de resistência. Coimbra: Coimbra Editora, 2009.

BAPTISTA, M.V. A Investigação em Serviço Social. Lisboa: CPIHTS, Centro Português de Investigação em História e Trabalho Social, 2001. 
COWLES, L.A.F. Social Work in the Health Field, a care perspective. 2. ed. New York: The Haworth Social Work Practice Press, 2003.

FERNANDES, E. Elementos para uma Cronologia do Serviço Social em Portugal. Intervenção Social, 1985, p. 2-3, 143-48.

FERREIRA, F.A.G. Sistemas de Saúde e seu Funcionamento. Lisboa: Fundação Calouste Gulbenkian, 1989.

História da Saúde e dos Serviços de Saúde em Portugal. Lisboa: Fundação Calouste Gulbenkian, 1990.

GONÇALVES, M.M.F. \& COSTA, J.B.M.F. O Sistema de Saúde Português (p. 91109). In: NUNES, R. Política de Saúde. Porto: Universidade Portucalense Infante D. Henrique, 2003.

GUADALUPE, S., GONÇALVES, A. M. Os números do Serviço Social nos cuidados de saúde primários: o caso da região centro de Portugal. Serviço Social \& Saúde, ano VII/VIII, n.7-8, 2009, p. 127-60.

ISSSC. Alguns apontamentos para a compreensão do ensino ministrado no Instituto Superior de Serviço Social de Coimbra. Intervenção Social, 1985, 2-3, p. 149-65.

JORGE, M. Sistema de Saúde Português: sua evolução, situação actual e futura. Revista dos Médicos, Federação Nacional dos Médicos, 1992, 3/4, p. 4-8.

MARTINELLI, M.L. Serviço Social na área da saúde: uma relação histórica. Intervenção Social, 28, 2003. p. 9-18.

MARTINS, A.M.C. Génese, Emergência e Institucionalização do Serviço Social Português. Lisboa: Fundação Calouste Gulbenkian e Fundação para a Ciência e a Tecnologia, 1999.

Génese, Emergência e Institucionalização do Serviço Social Português. 2 ed. Lisboa: eProgress . Encadernação Progresso, 1910. 
MATIAS, M.A. Génese e emergência do Serviço Social na Saúde. Intervenção Social, 20, 1999, p. 91-114.

- Génese, emergência e institucionalização do Serviço Social no Instituto Português de Oncologia. Intervenção Social, 23/24, 2001, p. 53-62.

PORTUGAL. GEPS, Gabinete de Estudos e Planeamento do Ministério da Saúde e Assistência. O Serviço Social no Sector da Saúde. Série de Documentos de Trabalho do Gabinete de Estudos e Planeamento da Secretaria de Estado da Saúde, n. ${ }^{\circ}$ 2, 1979. PORTUGAL. MS, Ministério da Saúde. Serviço Social da Saúde. Divisão de Estudos e Planeamento do Departamento de Recursos Humanos da Saúde do Ministério da Saúde, 1998.

MOURÃO, A. Crónica dos Hospitais da Universidade de Coimbra. Coimbra: HUC, 1994.

CDSS-OMS. Organização Mundial da Saúde. Redução das desigualdades no período de uma geração. Igualdade na saúde através da acção sobre os seus determinantes sociais. Relatório Final da Comissão para os Determinantes Sociais da Saúde. Portugal, Organização Mundial da Saúde, 2010.

TELES, I. O Serviço Social - a saúde - o hospital. Revista do Serviço de Educação Permanente dos Hospitais da Universidade de Coimbra, 1 (1), 1990, p. 39-43. 